\title{
Fluorinated 2-alkyl-2-oxazolines of high reactivity: Spacer-length induced acceleration for Cationic Ring-Opening polymerization as basis for triphilic block copolymer synthesis
}

Leonid I. Kaberova, Bart Verbraeken ${ }^{\mathrm{b}}$, Anna Riabtseva ${ }^{\mathrm{a}}$, Jiri Brus ${ }^{\mathrm{a}}$, Yeshayahu Talmon ${ }^{\mathrm{c}}$, Petr Stepanek ${ }^{\mathrm{a}}$, Richard Hoogenboom ${ }^{b}$, Sergey K. Filippov ${ }^{a}{ }^{*}$

anstitute of Macromolecular Chemistry, Academy of Sciences of the Czech Republic, Heyrovský Sq. 2, 16206 Prague 6, Czech Republic. E-mail: filippov@imc.cas.cz

bSupramolecular Chemistry Group, Department of Organic and Macromolecular Chemistry, Ghent University, Krijgslaan 281 S4, B-9000 Ghent, Belgium.

'Department of Chemical Engineering, Technion-Israel Institute of Technology, Haifa 3200003, Israel

\begin{abstract}
The synthesis of defined triphilic terpolymers with hydrophilic, lyophilic and fluorophilic blocks is an important challenge as basis for the development of multicompartment self-assembled structures with potential for, e.g., cascade catalysis and multi-drug loading. The synthesis of fluorophilic poly(2oxazoline)s generally suffers from a very low reactivity of fluorinated 2-oxazoline monomers in cationic ring-opening polymerization (CROP). We report a systematic study on overcoming the extremely low reactivity of 2-perfluoroalkyl-2-oxazolines in CROP by the insertion of methyl and ethyl hydrocarbon spacers between the 2-oxazoline ring and the trifluoromethyl group. The kinetic studies showed the gradual increase of the rate of polymerization with increasing of the hydrocarbon spacer length. The monomer with an ethyl spacer was found to have similar reactivity as 2-alkyl-2-oxazolines and allowed the synthesis of defined triphilic triblock copolymers.
\end{abstract}

Poly(2-oxazoline)s are widely used in many medical and biological applications ${ }^{1,2}$. The cationic ringopening polymerization (CROP) of 2-substituted-2-oxazolines can proceed at certain conditions in a living mode, which allows to synthesize defined polymers with very low dispersity. In combination with a variety of commercially and synthetically available monomers, it makes 2-oxazolines very attractive candidates for the design of amphiphilic polymer systems with controlled properties ${ }^{3,4,5}$. The majority of these systems is amphiphilic $\mathrm{AB}$ block and $\mathrm{ABA}$ triblock copolymers. However, in recent years, the behavior of hydrophilic-hydrophobic-fluorophilic $\mathrm{ABC}$ triblock copolymers has attracted significant attention as they form more complex self-assembled structures than traditional $\mathrm{AB}$ copolymers due to mutual incompatibility of all three blocks ${ }^{6,7,8,9}$. Such multicompartment self-assembled structures are highly interesting as for developing cascade catalysis or multidrug drug delivery by encapsulation incompatible catalysts or drugs into the separate compartments. 
The development of triphilic poly(2-oxazoline)s is severely hampered by the extremely low reactivity of fluorinated 2-oxazolines in CROP, representing the main limitation and challenge for the synthesis of aliphatic fluorophilic poly(2-oxazoline)s. Usually, the CROP of 2-alkyl-2-oxazolines proceeds via ionic propagation centers ${ }^{10}$. However, the presence of a strong electron-withdrawing perfluoroalkyl substituent in the 2-position of the 2-oxazoline ring extremely decreases the reactivity of the monomer and facilitates the transition of the active center into the less reactive covalent form ${ }^{11,12}$. The synthesis of such perfluoroalkyl poly(2-oxazoline)s with high degree of polymerization (more than 10 monomeric units) is associated with significant experimental difficulties (e.g., high temperature and long reaction times) making it practically impossible ${ }^{13}$.

To overcome this limitation, there is a need for novel fluorinated 2-oxazolines with higher reactivity. Recently, the polymerization of fluorinated 2-phenyl-2-oxazolines has been reported by Schubert et al. allowing the preparation of triblock copolymers and formation of multicompartment micelles ${ }^{14,15}$. A few examples of fluorinated poly(2-oxazoline)s based on monomers with an ethyl spacer between the fluorinated segment and the 2-oxazoline ring were also reported in works of Papadakis ${ }^{16}$ and Sogah ${ }^{17,18}$, where it was postulated that this decouples the fluorinated segment from the 2-oxazoline ring without providing kinetic evidence.

Here we present a detailed systematic study on increasing the reactivity of fluorinated 2-oxazoline monomers by insertion of hydrocarbon spacers. Therefore, new fluorine-containing 2-alkyl-2-oxazolines were developed having methyl and ethyl spacers between the terminal $\mathrm{CF}_{3}$-group and the 2-oxazoline ring. All fluorinated 2-oxazolines were synthesized by a standard method based on the synthesis of $N$-(betahaloethyl)amides followed by a ring-closing reaction to obtain the desired 2-oxazoline monomers.

2-Trifluoromethyl-2-oxazoline was synthesized on the basis of a literature procedure ${ }^{19}$. According to this method $\mathrm{N}$-(2-bromoethyl)trifluoroacetamide was obtained from ethyltrifluoroacetate by reaction with 2bromoethylamine hydrobromide. The second step was ring-closure using sodium hydride as base yielding 2-trifluoromethyl-2-oxazoline $\left(\mathrm{CF}_{3} \mathrm{Ox}\right)$.

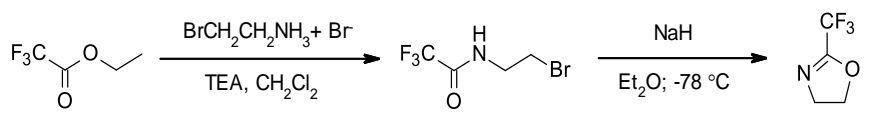

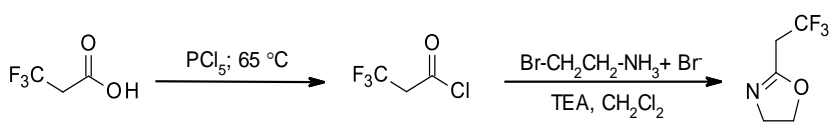

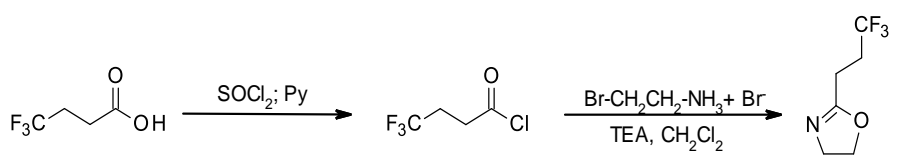

Fig.1. Synthesis scheme for the fluorinated 2-oxazoline monomers

The synthesis of 2-(2,2,2-trifluoroethyl)-2-oxazoline $\left(\mathrm{CF}_{3} \mathrm{MeOx}\right.$, a) and 2-(3,3,3-trifluoropropyl)-2oxazoline $\left(\mathrm{CF}_{3} \mathrm{EtOx}, \mathbf{b}\right)$ was started from the corresponding carboxylic acids that were converted to the more reactive acid chloride. The amide formation was performed with 2-bromoethylamine in presence of excess of triethylamine, directly yielding the ring-closed 2-oxazoline monomers. 
The polymerization kinetics of the three monomers was studied at standard polymerization conditions, being $140{ }^{\circ} \mathrm{C}$ in acetonitrile in a closed reaction vessel, at a monomer concentration of $1 \mathrm{M}$, with methyl ptoluenesulfonate (MeTos) as initiator and a target degree of polymerization of $100^{20}$. The conversion of the monomer was determined by gas chromatography (GC), whereas molecular weights were analyzed by size exclusion chromatography (SEC).

Under these conditions, $\mathrm{CF}_{3} \mathrm{Ox}$ revealed no noticeable conversion after 24 hours. Variation of temperature (up to $180{ }^{\circ} \mathrm{C}$ when degradation occurs) and the use of another solvent/initiator system (dichlorobenzene/silver triflate $(\mathrm{AgOTf})+\mathrm{MeTos})$ also gave no polymerization. This behavior can be ascribed to the strong electron-withdrawing effect of the trifluoromethyl group on the reactivity of the monomer and is in agreement with previous observations by Jordan and Papadakis for 2-perfluoroalkyl-2oxazolines $^{12}$.

The polymerization of $\mathrm{CF}_{3} \mathrm{MeOx}$ with a single methylene unit as spacer proceeds with acceptable rate and full monomer conversion was achieved after 2.5 hours under standard conditions (Figure 2a). However, the first order kinetic plot shows a continuous increase in slope indicative of slow initiation, i.e. during the polymerization more and more chains are initiated leading to faster monomer conversion, which can be ascribed to the low monomer nucleophilicity (Figure 2a). Due to this continuous initiation SEC revealed a very broad molar mass distribution that was not resolved from the system peak obstructing accurate integration (see supporting information Figure S1).
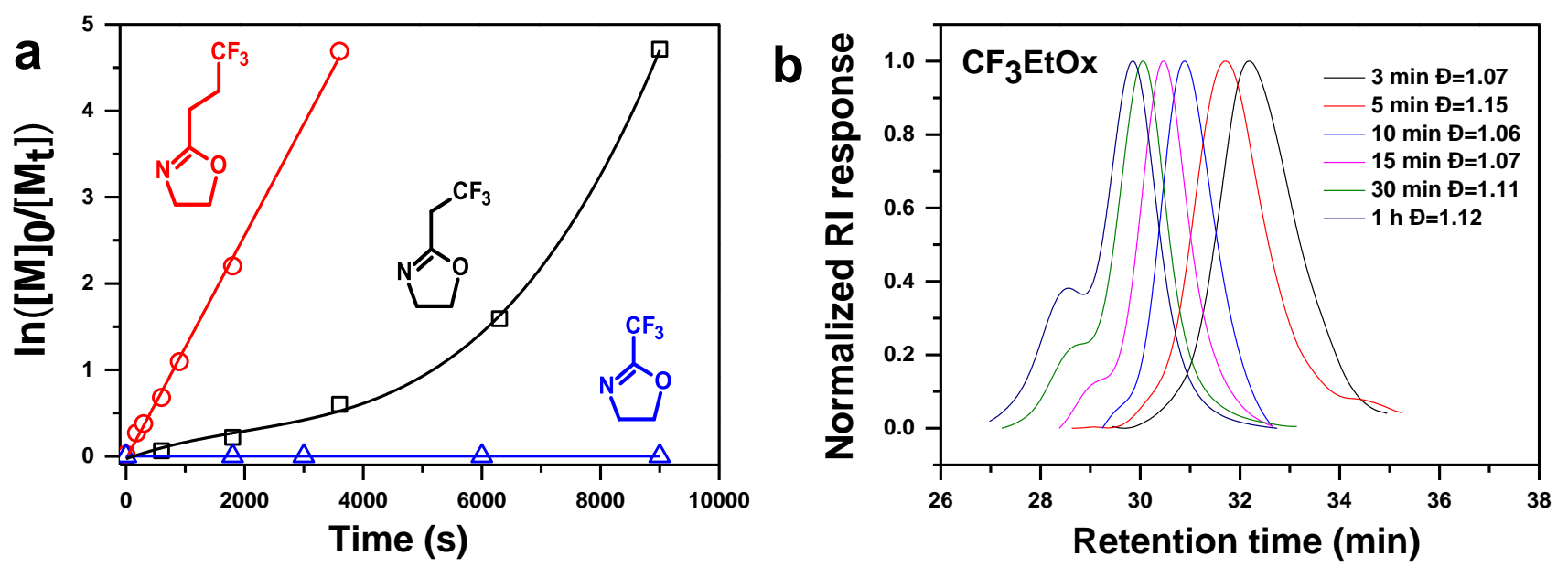

Fig.2. Kinetic plots for the cationic ring-opening polymerization (a) of $\mathrm{CF}_{3} \mathrm{Ox}$ (blue), $\mathrm{CF}_{3} \mathrm{MeOx}$ (black), $\mathrm{CF}_{3} \mathrm{EtOx}$ (red), and the SEC data for $\mathrm{CF}_{3} \mathrm{EtOx}(\mathrm{b})$. RI - Refractive Index.

Finally, the $\mathrm{CF}_{3} \mathrm{EtOx}$ monomer with a double methylene spacer shows the linear first order kinetics, typical for living CROP (Figure 2a). The SEC traces at various conversions show a narrow molar mass distribution with dispersity (Đ) well below 1.2 (Figure 2b). The appearance of the double molar mass shoulder at higher conversion is due to unavoidable chain transfer reactions that result in enamine end-capped polymers. Towards the end of the reaction, these enamine functional polymers react with living polymer chains inducing higher molar mass branched structures. This shoulder is resolved in the high resolution SEC system, but does not strongly influence the $Đ$. The polymerization rate constant $\left(\mathrm{k}_{\mathrm{p}}\right)$, calculated from the slope of the first order kinetic plot, was found to be $\mathrm{k}_{\mathrm{p}}=129 * 10^{-3} \mathrm{~L}^{*} \mathrm{~mol}^{-1 *} \mathrm{~s}^{-1}$, which is very similar to nonfluorinated 2-alkyl-2-oxazolines indicating that the electron-withdrawing effect of the $\mathrm{CF}_{3}$-group on the 2- 
oxazoline ring is completely suppressed when introducing an ethyl spacer ${ }^{21}$. From these kinetic studies it can be concluded that only the $\mathrm{CF}_{3}$ EtOx is applicable for the synthesis of block copolymers.

Next, we continued the preparation of a series of amphiphilic block copolymers by CROP with sequential monomer addition. More specifically, diblock copolymers were prepared by first polymerizing $\mathrm{MeOx}$ up to $>98 \%$ conversion followed by addition of $\mathrm{CF}_{3} \mathrm{EtOx}$ while triblock copolymers of $\mathrm{MeOx}, \mathrm{CF}_{3} \mathrm{EtOx}$ and 2-octyl-2-oxazoline (OctOx, chosen as hydrophobic comonomer immiscible with $\mathrm{CF}_{3} \mathrm{EtOx}$ ) were prepared by first polymerizing $\mathrm{MeOx}$ up to $>98 \%$ conversion, followed by polymerization of the second monomer up to $>98 \%$ conversion followed by addition of the third monomer and polymerization up to $>98 \%$ conversion. All polymerizations were terminated by the addition of $1 \mathrm{M} \mathrm{KOH}$ in methanol to the polymerization mixture. The structural details and characterization data of the synthesized diblock and triblock copolymers are summarized in Table 1 demonstrating that well defined polymers were obtained with $Đ<1.4$. Importantly, TB2 and TB3 have similar $Đ$ indicating that the order of addition of monomers does not make a difference, as anticipated based on their similar $\mathrm{k}_{\mathrm{p}}$.

Table 1. Characteristics of the synthesized block copolymers

\begin{tabular}{c|c|c|c|c|c}
\hline & Composition (NMR) & $\begin{array}{c}M_{\mathrm{n}}(\mathrm{SEC}- \\
\mathrm{MALS}), \\
\mathrm{g} / \mathrm{mol}\end{array}$ & $\begin{array}{c}M_{\mathrm{w}}(\mathrm{SEC}- \\
\mathrm{MALS}), \\
\mathrm{g} / \mathrm{mol}\end{array}$ & $\begin{array}{c} \pm(\text { SEC- } \\
\text { MALS })\end{array}$ & $\begin{array}{c}\text { Monomer ratio } \\
\text { (NMR) }\end{array}$ \\
\hline $\mathrm{DB} 1$ & $\mathrm{MeOx}_{38}-\mathrm{CF}_{3} \mathrm{EtOx}_{17}$ & 6000 & 7200 & 1.20 & $2.2: 1$ \\
$\mathrm{DB} 2$ & $\mathrm{MeOx}_{47}-\mathrm{CF}_{3} \mathrm{EtOx}_{27}$ & 8500 & 11000 & 1.30 & $1.7: 1$ \\
$\mathrm{DB} 3$ & $\mathrm{MeOx}_{39}-\mathrm{CF}_{3} \mathrm{EtOx}_{28}$ & 7500 & 10300 & 1.37 & $1.4: 1$ \\
$\mathrm{DB} 4$ & $\mathrm{MeOx}_{23}-\mathrm{CF}_{3} \mathrm{EtOx}_{25}$ & 6100 & 8100 & 1.33 & $0.9: 1$ \\
$\mathrm{~TB} 1$ & $\mathrm{MeOx}_{28}-\mathrm{OctOx}_{9}-\mathrm{CF}_{3} \mathrm{EtOx}_{12}$ & 6300 & 8000 & 1.27 & $2.3: 0.7: 1$ \\
$\mathrm{~TB} 2$ & $\mathrm{MeOx}_{49}-\mathrm{OctOx}_{11}-\mathrm{CF}_{3} \mathrm{EtOx}_{16}$ & 9000 & 11800 & 1.31 & $3: 0.7: 1$ \\
$\mathrm{~TB} 3$ & $\mathrm{OctOx}_{12}-\mathrm{MeOx}_{52}-\mathrm{CF}_{3} \mathrm{EtOx}_{18}$ & 9700 & 13500 & 1.39 & $2.8: 1: 0.65$ \\
\hline
\end{tabular}

In final part of this work, a preliminary evaluation of the self-assembly potential of the synthesized partially fluorinated block copolymers in water was performed. It was proven by dynamic light scattering (DLS) that all polymers can be molecularly dissolved in a number of common organic solvents, including methanol, ethanol and chloroform. The aqueous solutions of block copolymers were prepared by using a solvent exchange method from methanol to water by dialysis. A DLS study of the obtained aqueous solutions of the $\mathrm{MeOx}-\mathrm{CF}_{3} \mathrm{EtOx}$ diblock copolymers revealed the presence of particles with hydrodynamic diameters in the range of 17-25 nm; attributed to micelles (see supporting information Figure S2). The size of the aggregates resulting from the triblock copolymer is larger, up to $30-50 \mathrm{~nm}$, and the appearence of a certain fraction of larger aggregates with a hydrodynamic diameter in the range of 150-300 nm was observed (see supporting information Figure S3). In addition, the middle position of the hydrophilic block in the TB3 triblock caused the formation of larger aggregates compared to the same composition TB2 
triblock with terminal hydrophilic block (see supporting information Figure S3). On the cryo-TEM image of triblock TB1 (1 wt. \%) (Figure 3), spherical aggregates with a mean diameter of $15 \mathrm{~nm}$ are observed representing the hydrophobic core of polymer micelles. A small population of large spherical objects was also found in the cryo-TEM image, which could correspond to the larger particles observed by DLS.

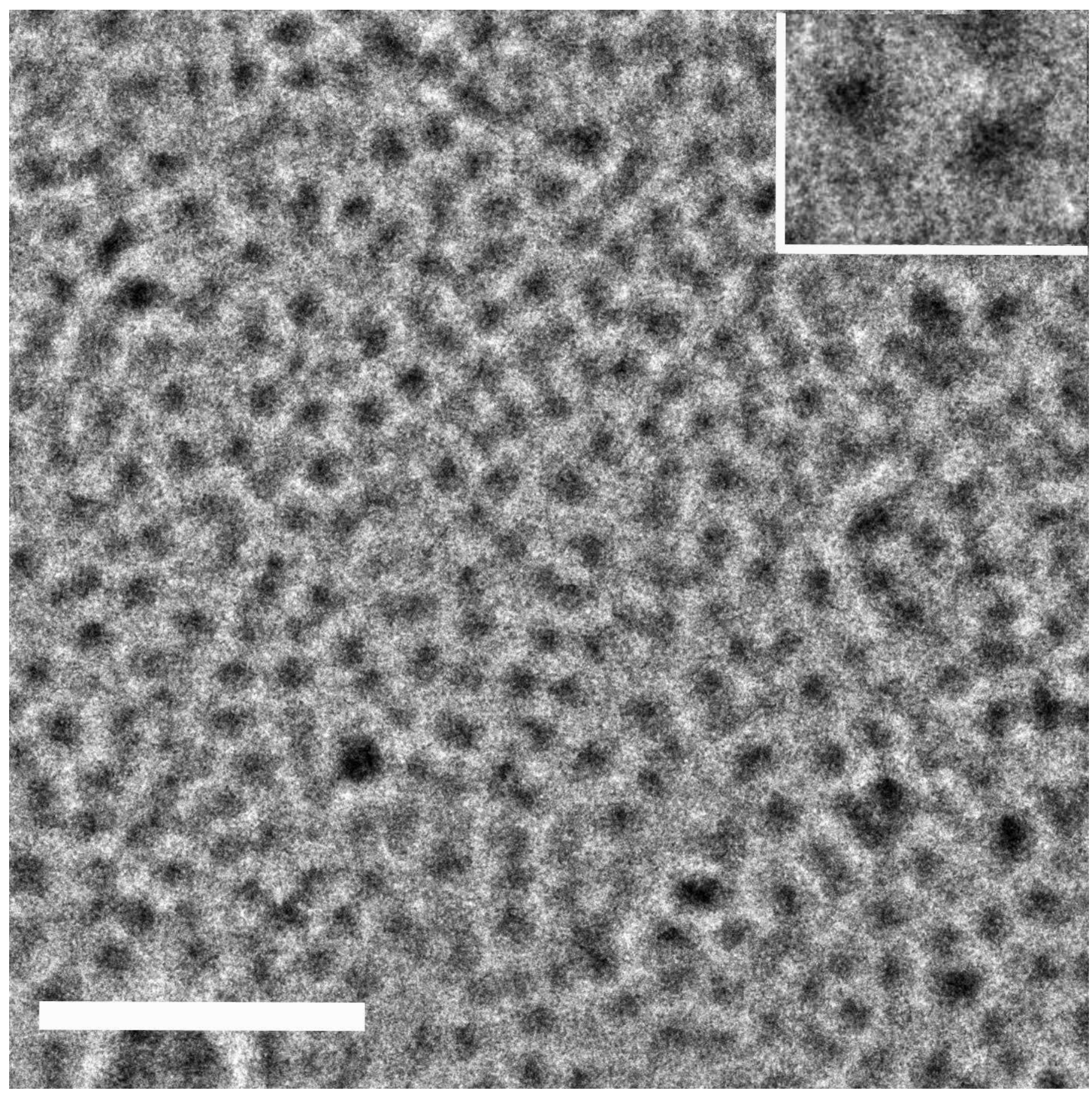

Fig. 3. Cryo-TEM image micelles of triblock TB1. The scale bar equals $100 \mathrm{~nm}$.

To conclude, a systematic study on the insertion of a spacer between the fluorinated fragment and the 2oxazoline ring was reported revealing its effect on the monomer reactivity in CROP. Two new fluorinated 2-oxazoline monomers, namely $\mathrm{CF}_{3} \mathrm{MeOx}$ and $\mathrm{CF}_{3} \mathrm{EtOx}$, were synthesized and characterized. The kinetic study showed a gradual increase of monomer reactivity in CROP with insertion of methylene spacers between the trifluoromethyl group and the 2-oxazoline ring. Insertion of two methylene groups allows 
complete suppression of the electron-withdrawing effect of the trifluoromethyl group, yielding similar reactivity as non-fluorinated 2-alkyl-2-oxazolines. Subsequently, a set of di- and triblock copolymers with $\mathrm{MeOx}$ as hydrophilic block and $\mathrm{CF}_{3}$ EtOx based fluorophilic block with polydispersity in the range of 1.21.4 was synthesized. The self-assembly potential of the synthesized block copolymers in aqueous solution was demonstrated by DLS. Cryo-TEM revealed the presence of micelles in aqueous solution based on the triphilic triblock copolymers. Future work will focus on more in-depth studies on the self-assembly behaviour of amphiphilic diblock and triblock copolymers based on $\mathrm{CF}_{3} \mathrm{EtOx}$.

\section{Author information}

Corresponding Author

* E-mail: filippov@imc.cas.cz

\section{ORCID}

Sergey Filippov:

\section{Notes}

The authors declare no competing financial interest.

\section{Acknowledgments}

This work was supported by Czech Science Foundation GA CR (grant 17-00973S). S. Filippov and R. Hoogenboom acknowledge the support of the mobility project AV ČR - FWO (FWO-17-05). S. Filippov., L. Kaberov., and A. Riabtseva acknowledge Bedrich Porsch and Zuzana Masinova (Institute of Macromolecular Chemistry AS CR, v.v.i., Prague, Czech Republic) for characterization of polymers by GPC, and Anna Bogomolova (Institute of Macromolecular Chemistry AS CR, v.v.i., Prague, Czech Republic) for help with the cryo-TEM studies. B. Verbraeken and R. Hoogenboom acknowledge support from the institute for innovation and technology (IWT), Flanders for funding. The cryo-TEM work was performed at the Technion Center for Electron Microscopy of Soft Matter, Haifa, Israel, supported by the Technion Russell Berrie Nanotechnology Institute (RBNI). We thank Judith Scmmidt for taking the cryoTEM images.

\section{References}

(1) Luxenhofer, R.; Schulz, A.; Roques, C.; Li, S.; Bronich, T. K.; Batrakova, E. V.; Jordan, R.; Kabanov, A. V. Biomaterials 2010, 31 (18), 4972-4979.

(2) Luxenhofer, R.; Sahay, G.; Schulz, A.; Alakhova, D.; Bronich, T. K.; Jordan, R.; Kabanov, A. V. J. Control. Release 2011, 153 (1), 73-82.

(3) Hoogenboom, R.; Schlaad, H. Polymers (Basel). 2011, 3 (4), 467-488. 
(4) Hoogenboom, R. Angew. Chemie - Int. Ed. 2009, 48 (43), 7978-7994.

(5) Schlaad, H.; Diehl, C.; Gress, A.; Meyer, M.; Levent Demirel, A.; Nur, Y.; Bertin, A. Macromol. Rapid Commun. 2010, 31 (6), 511-525.

(6) Kubowicz, S.; Baussard, J. F.; Lutz, J. F.; Thünemann, A. F.; Von Berlepsch, H.; Laschewsky, A. Angew. Chemie - Int. Ed. 2005, 44 (33), 5262-5265.

(7) Moughton, A. O.; Hillmyer, M. A.; Lodge, T. P. Macromolecules 2012, 45 (1), 2-19.

(8) Li, Z. Science (80-. ). 2004, 306 (5693), 98-101.

(9) Pochan, D. J. Science (80-. ). 2004, 306 (5693), 94-97.

(10) Verbraeken, B.; Monnery, B. D.; Lava, K.; Hoogenboom, R. Eur. Polym. J. 2017, 88, 451-469.

(11) Miyamoto, M.; Aoi, K.; Saegusa, T. Macromolecules 1988, No. 21, 1880-1883.

(12) Saegusa, T.; Chujo, Y.; Aoi, K.; Miyamoto, M. Makromol. Chem., Macromol. Symp. 1990, No. 32, $1-10$.

(13) Miyamoto, M.; Aoi, K.; Saegusa, T. Macromolecules 1991, 24 (1), 11-16.

(14) Lobert, M.; Thijs, H. M. L.; Erdmenger, T.; Eckardt, R.; Ulbricht, C.; Hoogenboom, R.; Schubert, U. S. Chem. - A Eur. J. 2008, 14 (33), 10396-10407.

(15) Kempe, K.; Hoogenboom, R.; Hoeppener, S.; Fustin, C.-A.; Gohy, J.-F.; Schubert, U. S. Chem. Commun. 2010, 46 (35), 6455.

(16) Ivanova, R.; Komenda, T.; Bonné, T. B.; Lüdtke, K.; Mortensen, K.; Pranzas, P. K.; Jordan, R.; Papadakis, C. M. Macromol. Chem. Phys. 2008, 209 (21), 2248-2258.

(17) Kaku, M.; Grimminger, L. C.; Sogah, D. Y.; Haynie, S. I. J. Polym. Sci. Part A Polym. Chem. 1994, 32 (11), 2187-2192.

(18) Rodriguez-Parada, J. M.; Kaku, M.; Sogah, D. Y. Macromolecules 1994, 27 (6), 1571-1577.

(19) ISHIKAWA, N.; AKIRA, S. EP0151449 (A2) - Process for the production of fluorine containing $\mathrm{N}$-(beta-bromoethyl)amide and of 2-(perfluoroalkyl)-1,3-oxazoline., 1985.

(20) Wiesbrock, F.; Hoogenboom, R.; Leenen, M. A. M.; Meier, M. A. R.; Schubert, U. S. Macromolecules 2005, 38 (12), 5025-5034.

(21) Hoogenboom, R.; Fijten, M. W. M.; Thijs, H. M. L.; van Lankvelt, B. M.; Schubert, U. S. Des. Monomers Polym. 2005, 8 (6), 659-671.

(22) Skrabania, K.; Berlepsch, H. V.; Böttcher, C.; Laschewsky, A. Macromolecules 2010, 43 (1), 271281.

(23) Skrabania, K.; Laschewsky, A.; Berlepsch, H. V.; Böttcher, C. Langmuir 2009, 25 (13), $7594-$ 7601. 
Fluorinated 2-alkyl-2-oxazolines of high reactivity: Spacer-length induced acceleration for Cationic Ring-Opening polymerization as basis for triphilic block copolymer synthesis

Leonid I. Kaberova, Bart Verbraeken ${ }^{\mathrm{b}}$, Anna Riabtseva ${ }^{\mathrm{a}}$, Jiri Brus ${ }^{\mathrm{a}}$, Yeshayahu Talmon ${ }^{\mathrm{c}}$, Petr Stepanek ${ }^{\mathrm{a}}$, Richard Hoogenboom ${ }^{b}$, Sergey K. Filippova, ${ }^{a}$

${ }^{a}$ Institute of Macromolecular Chemistry, Academy of Sciences of the Czech Republic, Heyrovsky Sq. 2, 162 06 Prague 6, Czech Republic. E-mail: filippov@imc.cas.cz

${ }^{b}$ Supramolecular Chemistry Group, Department of Organic and Macromolecular Chemistry, Ghent University, Krijgslaan 281 S4, B-9000 Ghent, Belgium.

${ }^{c}$ Department of Chemical Engineering, Technion-Israel Institute of Technology, Haifa 3200003, Israel

\begin{abstract}
The synthesis of fluorophilic poly(2-oxazoline)s generally suffers from a very low reactivity of fluorinated 2-oxazoline monomers in cationic ring-opening polymerization (CROP). We report a systematic study on overcoming the extremely low reactivity of 2-perfluoroalkyl-2-oxazolines in CROP by the insertion of methyl and ethyl hydrocarbon spacers between the 2-oxazoline ring and the trifluoromethyl group. The kinetic studies showed the gradual increase of the rate of polymerization with increasing of the hydrocarbon spacer length. The monomer with an ethyl spacer was found to have similar reactivity as 2-alkyl-2oxazolines and allowed the synthesis of defined triphilic triblock copolymers.
\end{abstract}




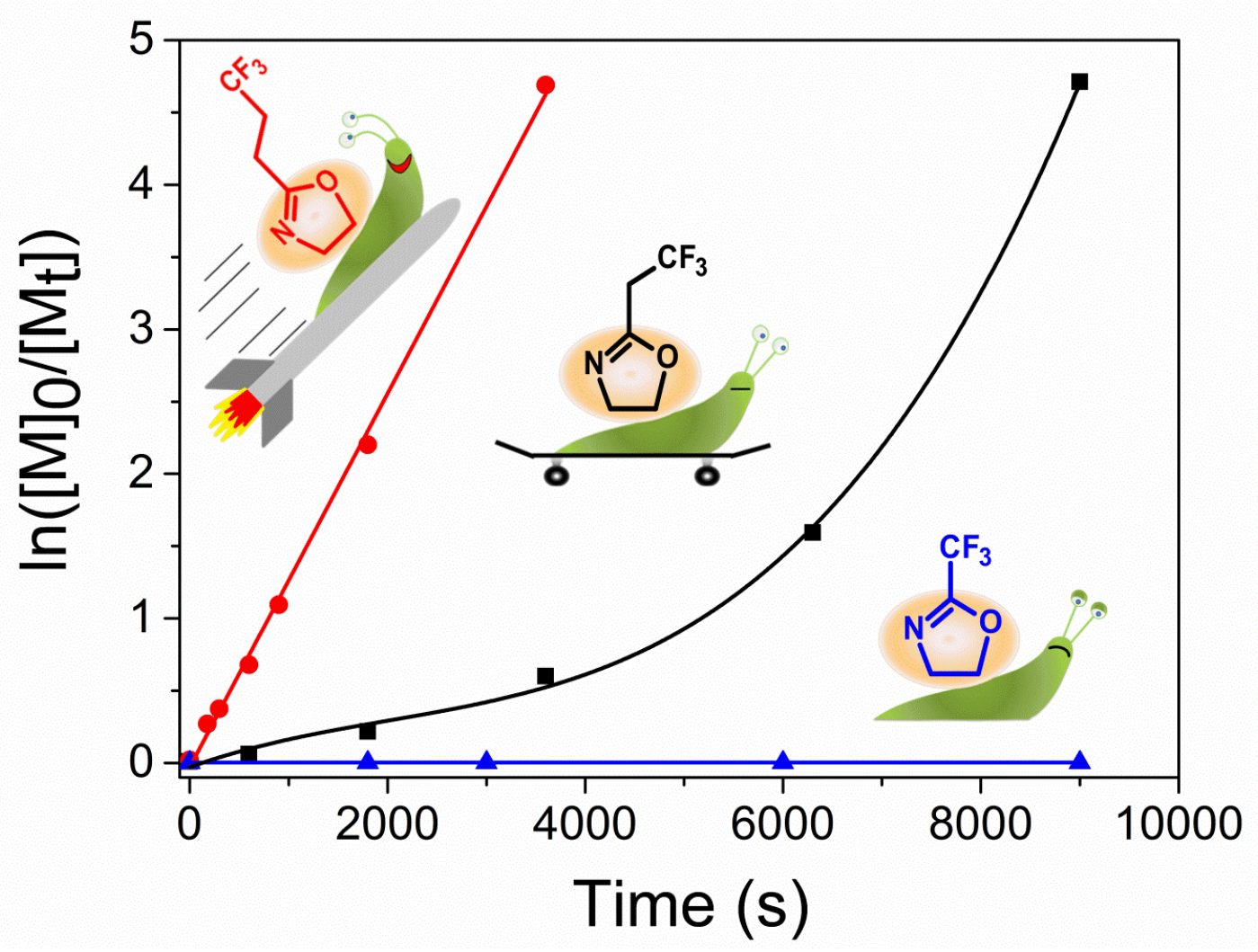

